\title{
Electrohydraulic lithotripsy for pancreatic duct stones under temporary 6-mm fully covered metal stent placement
}
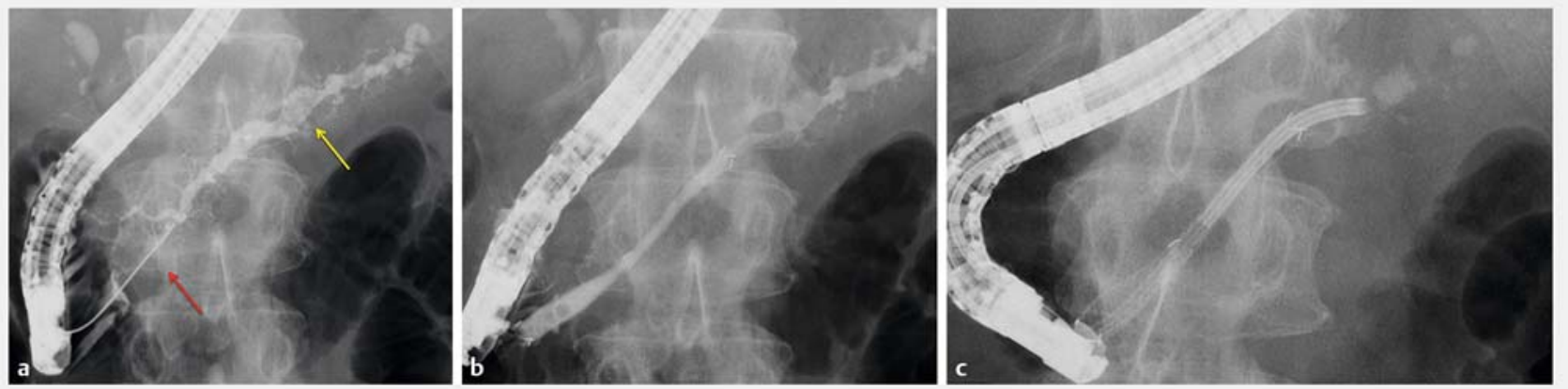

- Fig. 1 Radiographic images showing: a the pancreatic head stricture (red arrow) and pancreatic stone in the pancreatic body (yellow arrow); b a fully covered self-expandable metal stent in position across the stricture site; $\mathbf{c}$ the digital single-operator pancreatoscope inserted through the metal stent.

Pancreatic duct stones (PDSs) can be treated by electrohydraulic lithotripsy (EHL) under endoscopic retrograde cholangiopancreatography (ERCP) guidance $[1,2]$. The availability of the digital single-operator cholangioscope (SpyGlass DS; Boston Scientific, Natick, Massachusetts, USA) $[3,4]$ allows EHL to be more easily performed. However, if patients' conditions are complicated by main pancreatic duct (MPD) stenosis, EHL for PDSs under pancreatoscopy guidance may be challenging. Herein, we describe some technical tips for the use of EHL to treat a PDS with placement of a temporary 6-mm fully covered self-expandable metal stent (FCSEMS).

A 49-year-old man was admitted to our hospital because of abdominal pain due to chronic pancreatitis. On computed tomography (CT) scanning, a pancreatic stone was seen in the pancreatic body. Stone removal under ERCP was therefore attempted.

A duodenoscope (JF260V; Olympus Optical, Tokyo, Japan) was inserted into the ampulla of Vater, and an ERCP catheter (MTW Endoskopie, Düsseldorf, Germany) was inserted into the MPD. Pancreatography showed a tight stricture in the pancreatic head ( $\vee$ Fig. 1 a) and a stone in the pancreatic body. Although

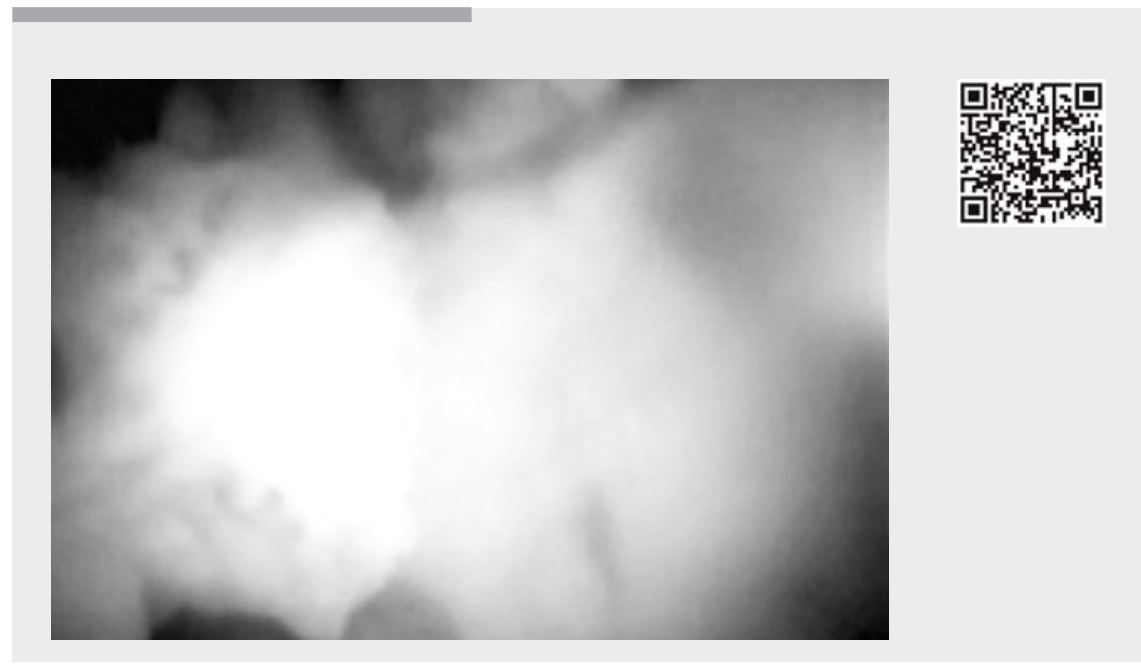

$\nabla$ Video 1 A digital single-operator pancreatoscope is inserted into the main pancreatic duct through the metal stent. Electrohydraulic lithotripsy is attempted and fragmentation of stones is successfully obtained.

balloon dilation was performed, it was not possible to achieve enough dilation. Therefore, to allow insertion of the pancreatoscope, placement of a metal stent (6-mm $\times 6-\mathrm{cm}$, Niti-S Biliary S-Type Stent Long Suture; TaeWoong Medical, Seoul, Korea) was performed ( $\bullet$ Fig. $\mathbf{1}$ b).

After 1 day, with the FCSEMS fully expanded, the pancreatoscope was inserted into the MPD through the stent
( $\vee$ Fig.1c; $\vee$ Video 1). The pancreatic stone could be clearly observed and EHL was attempted. An electrohydraulic shock wave generator (Lithotron EL27; Walz Elektronik $\mathrm{GmbH}$ ) was used to generate shock waves of increasing frequency, which were applied as a continuous sequence of discharges during EHL. EHL was successfully performed and the stone was subsequently removed using 


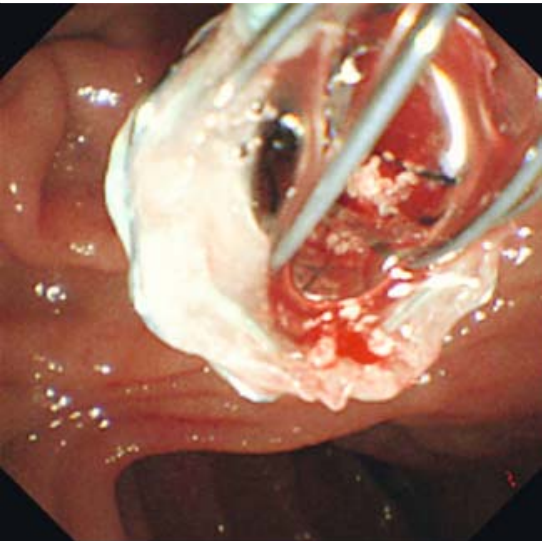

- Fig. 2 Endoscopic image showing the stone being successfully removed using a basket catheter passed through the metal stent.

a basket catheter through the FCSEMS ( $\triangleright$ Fig.2). Finally, the FCSEMS was removed and a plastic stent was placed instead, without any adverse events ( Fig.3).

The use of our technique may be indicated, even in patients whose management is complicated by an MPD stricture.

Endoscopy_UCTN_Code_TTT_1AR_2AI

Competing interests

None

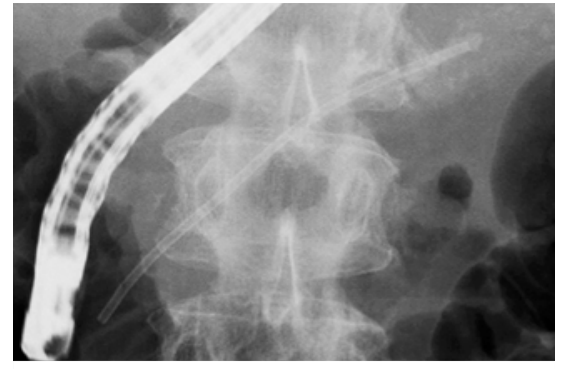

- Fig.3 Radiographic image showing a plastic stent that was placed after completion of the procedure and removal of the temporary metal stent.
The authors

Takeshi Ogura, Atsushi Okuda, Akira Miyano, Nobu Nishioka, Kazuhide Higuchi

2nd Department of Internal Medicine, Osaka

Medical College, Osaka, Japan

\section{Corresponding author}

\section{Takeshi Ogura, MD}

2nd Department of Internal Medicine, Osaka Medical College, 2-7 Daigakuchou, Takatsukishi, Osaka 569-8686, Japan Fax: +81-72-6846532

oguratakeshi0411@yahoo.co.jp

\section{References}

[1] Bekkali NL, Murray S, Johnson G] et al. Pancreatoscopy-directed electrohydraulic lithotripsy for pancreatic stones in painful chronic pancreatitis using SpyGlass. Pancreas 2017; 46: $528-530$

[2] Trikudanathan G, Freeman ML. Electrohydraulic lithotripsy of large pancreatic duct stones by using digital pancreatoscopy. Gastrointest Endosc 2016; 83: 1285 - 1296

[3] Ogura T, Imanishi M, Kurisu Y et al. Prospective evaluation of digital single-operator cholangioscope diagnostic and therapeutic procedures (with videos). Dig Endosc 2017; 29: $782-789$

[4] Tanaka R, Itoi T, Honjo M et al. New digital cholangiopancreatoscopy for diagnosis and therapy of pancreaticobiliary diseases (with videos). J Hepatobiliary Pancreat Sci 2016; 23: $220-226$

\section{Bibliography}

DOI https://doi.org/10.1055/a-0601-6673

Published online: 9.5.2018

Endoscopy 2018; 50: E177-E178

(c) Georg Thieme Verlag KG

Stuttgart · New York

ISSN 0013-726X

\section{ENDOSCOPY E-VIDEOS \\ https://eref.thieme.de/e-videos}

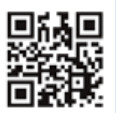

Endoscopy E-Videos is a free access online section, reporting on interesting cases and new

techniques in gastroenterological endoscopy. All papers include a high quality video and all contributions are freely accessible online.

This section has its own submission website at https://mc.manuscriptcentral.com/e-videos 